\title{
Evaluation of potential particulate/colloidal TEP foulants on a pilot scale SWRO desalination study
}

\author{
Sheng Li, Shahnawaz Sinha, Noreddine Ghaffour, TorOve Leiknes and Gary L. Amy \\ Water Desalination and Reuse Center (WDRC), Division of Biological and Environmental Science and Engineering \\ (BESE), King Abdullah University of Science and Technology (KAUST), Thuwal 23955-6900, Saudi Arabia, Tel. \\ +966-544700728, Email: Shahnawaz.Sinha@kaust.edu.sa
}

\begin{abstract}
This pilot study investigated the variation of potential foulants and different fractions of transparent exopolymer particles (TEP), along the treatment scheme under different conditions. The objectives are to provide a comprehensive understanding on which fraction of TEP is more problematic in seawater reverse osmosis (SWRO) fouling, and which pretreatment can better reduce the concentration of TEP. Results showed that TEP deposited on the RO membranes, and the extent of RO fouling increased with the increase of TEP concentration in RO feed water. More TEP was produced in water after chlorination, probably because of the breakdown of bacterial cells and thus the release of internal exopolymers. Moreover, the cartridge filters could behave as an incubator for the regrowth of bacteria deactivated by chlorination and a spot for potential foulant (bacterial TEP) production, and thus enhance the RO membranes fouling. The presence of residual iron and addition of phosphate based antiscalant may also contribute to the higher biofouling of RO membranes. This pilot study provided an opportunity to identify the TEP related issues under different operational conditions in RO desalination of Red Sea water.
\end{abstract}

Keywords: TEP; SWRO; Fouling; Chlorination; Cartridge filters; Residual iron.

\section{Introduction}

Because of the shortage of fresh water sources, seawater desalination is a potential solution for water supply in the Middle East region. Since 1980s, membrane technology has become the main technology applied in the desalination field due to its lower energy consumption compared to the traditional thermal technology [1]. Nowadays, about $63 \%$ of established desalination capacity around the world is using membrane technology, mainly reverse osmosis (RO). RO is good at 
removing the microorganisms, salts and organics from seawater, but membrane fouling issues are still a big obstacle in SWRO desalination.

Transparent exopolymer particles (TEP) and TEP precursors have been reported as potential foulants in SWRO membrane filtration [2-4]. TEP is mainly composed of acidic polysaccharides and/or protein, and operationally defined as particles larger than $0.4 \mu \mathrm{m}$ and stainable with alcian blue [5]. Spontaneous self-assembly of dissolved precursors is a major process of TEP formation $[6,7]$. Both bacteria and algae have been generally considered to be major source of TEP in marine ecosystems $[8,9]$, either releasing dissolved TEP precursors during exponential growth $[9,10]$ or excreting TEP directly via sloughing and lysis of senescent cells [11]. It has been reported that algal TEP contains more polysaccharides than bacterial TEP, while the protein content in bacterial TEP is higher than algal TEP . Even after removing the particulate TEP $(>0.4$ $\mu_{\mathrm{m}}$ ), the remaining bacterial TEP precursors can lead to a severe RO membrane fouling [13]. It has also been reported that algae-derived TEP substances can cause fouling of ultrafiltration (UF) and RO membranes [14].

In the Red Sea region, membrane based desalination plant consists mainly of: intake, chemical addition, in-line coagulation, dual media filters (DMF), cartridge filters and RO process. This traditional treatment scheme often suffers from fouling issues. Low pressure membranes, such as UF, are also used with/without combination with conventional pre-treatment processes. The performance of pre-treatments is normally evaluated by the fouling index, mainly the silt density index (SDI). Other fouling indices, such as modified fouling index (MFI) are developed but not used at industrial scale yet [15]. Lot of recommendations in terms of SDI value of RO feed water have been reported by researchers to improve the $\mathrm{RO}$ pretreatments and reduce fouling in the RO unit $[16,17]$. However, these fouling indices are related to the amount and size of particles in seawater. Organic and biological fouling issues are still a challenge for the desalination plant in this region. Especially during the algal bloom season, a considerable amount of TEP/TEP precursors could be produced. In 2008, some of desalination plants were forced to shut down for a couple of months during the algal bloom events because of the clogging problem of pretreatments and fouling of RO units, probably caused by the produced TEP/TEP precursors [18]. It is possible that TEP/TEP precursors form a chemical conditioning layer on the membrane surface when they deposit on membranes. This chemical conditioning layer can be thickened by the accumulation of deposited TEP/TEP precursors. Moreover, bacteria may agglutinate and 
grow on this TEP conditioning layer. Consequently, a biofilm can be formed and enhanced with the growth of bacteria on the conditioning layer. However, there is limited research evaluating the variation of TEP/TEP precursors (potential foulants) along the treatment scheme, especially the variation of different fractions of TEP substances in the treatment scheme. Some of the measures were applied to reduce seawater reverse osmosis (SWRO) membrane fouling, such as chlorination and filtration, but their impacts on TEP/TEP precursors concentration are not clear. Chlorination has been considered as a main method to control the RO biofouling by destroying bacteria in water to be treated. Karnaugh et al. [19] showed the good biofouling control by periodic direct chlorination. Friedler et al. [20] reported the success of chlorination as pretreatment in grey water desalination. However, Khan et al. [21] reported opposite results on cellulose triacetate (CTA) RO membranes and indicated that both continuous and intermittent chlorination were not capable on preventing biofilm formation. Because of these opposite findings from different researchers, the impact of chlorination on the biofouling of $\mathrm{RO}$ membranes is still not clear, especially the relationship between chlorination and the concentration of TEP/TEP precursors (potential foulants) in seawater.

Cartridge filter is used as a last-step protection to ensure that the RO feed water with low SDI values. However, it is possible that the cartridge filters can serve as a hub for the regrowth of bacteria. Khan et al. [21] indicated in their research that one of the failures of chlorination on preventing biofouling is the chlorine adaptation of certain bacterial populations. Especially, in order to protect the polyamide RO membranes (polyamide material is easy to be damaged by chlorine), sodium bisulfate (SBS) is normally used in front of cartridge filter to quench the residual chlorine before the seawater enters the RO units. The removal of residual chlorine may even enhance the regrowth of chlorine adapted bacteria in the cartridge filters. If the bacteria grew in cartridge filters, they would release TEP/TEP precursors into the RO feed and then foul the RO membranes. To verify this, it is interesting to investigate the variation of TEP/TEP precursors over the cartridge filters.

In summary, this pilot study investigated the variation of different fractions of TEP substances along the treatment scheme under different conditions, to provide a comprehensive understanding on variation of different fractions of TEP and their impacts on SWRO membrane fouling. The effectiveness of pretreatments on potential foulants (TEP) removal were also evaluated. 


\section{Materials and methods}

\subsection{Description of the pilot plant}

97 The pilot desalination plant was designed to mimic the full-scale RO membrane based plant.

98 Real Red Sea water was used as feed solution. The design was based on the visits of four full99 scale SWRO desalination plants located in different regions of Saudi Arabia and consisted of 100 open water intake, pre-chlorination, followed by acid addition (lowering $\mathrm{pH}$ ) and in-line 101 coagulation followed by DMF, $5 \mu \mathrm{m}$ cartridge filter $(\mathrm{CF})$, and spiral wound SWRO membranes, 102 as shown in Figure 1. Chemicals (including chlorine, sulfuric acid, and coagulant) were injected 103 after the intake pumping and then properly mixed by a static mixer. Phosphate based antiscalant 104 and sodum bisulfate (SBS) were injected in front of the cartridge filters to prevent scaling on 105 downstream RO membranes and quench residual chlorine, respectively.

106 The DMF is composed of $12.7 \mathrm{~cm}$ of gravel and $35.5 \mathrm{~cm}$ of sand; the filtration rate of DMF was $10713 \mathrm{~m} / \mathrm{hr}$, with a treatment capacity up to $18 \mathrm{~m}^{3} / \mathrm{hr}$; backwash pressure of 0.7-1.2 bar. After the 108 DMF treatment, pretreated seawater passed through a $5 \mu \mathrm{m}$ cartridge filter (preventing the 109 entrance of big particles into the SWRO unit) and then was used as feed water for SWRO.

110 The SWRO pilot system was loaded with two DOW SW30-4040 RO membranes ( with a total 111 surface area of $14.8 \mathrm{~m}^{2}$ ). The SWRO unit (AMI, USA) was equipped with two pressure vessels,

112 and each vessel with one membrane element. The Pilot was operated at $0.5 \mathrm{~m}^{3} / \mathrm{hr}$ feed flow with $113 \quad 38-40 \%$ recovery rate. 
(a)

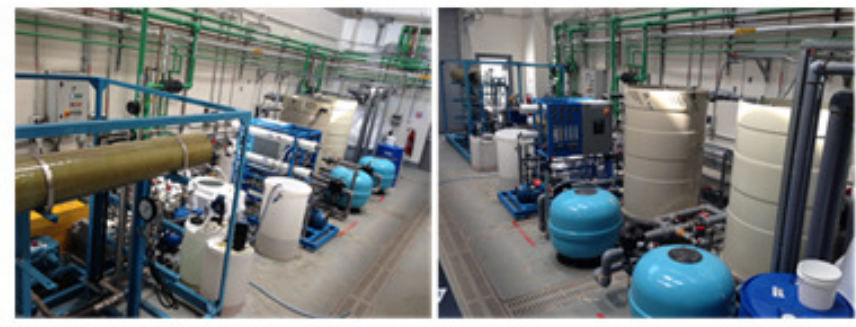

(b)

Spiral wound SWRO

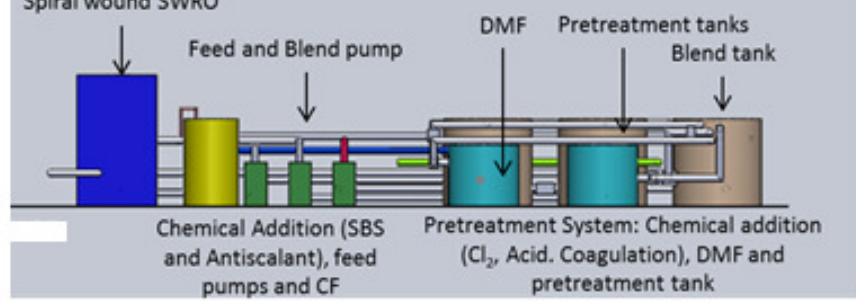

Sampling (6) (5) (4) (3) (2) (1)

1. Raw seawater (before chemical addition)

2. Seawater after chemical addition

(i.e., chlorination, acidification, coagulation)

3. After DMF filtration (from pretreatment tank)

4. After CF filtration

5. SWRO Permeate water

6. SWRO concentrate water

114

115 Figure 1: (a) Pilot plant layout and (b) sampling locations.

116

117

118

119

120

121

122

123

124

125

126

127

128

\subsection{Chemicals used} Red Sea. 2.3 Experimental runs
Sodium hypochlorite $(\mathrm{NaOCl})$ was used to disinfect incoming seawater and to maintain proper chlorine residuals in water before entering RO system. Sulfuric acid $\left(\mathrm{H}_{2} \mathrm{SO}_{4}\right)$ was applied to adjust $\mathrm{pH}$ for the incoming seawater and to maintain targeted water $\mathrm{pH}$ (6.5) for coagulation. $\mathrm{FeCl}_{3}$ (Sigma aldrich) was selected as coagulant in this study to improve removals of organic and particulate substances. Antiscalant (Berkosafe-SW) was added before the cartridge filter (CF) to prevent scaling. SBS (Sigma Aldrich) was continuously injected on the suction side of the highpressure pump (HPP) to quench residual chlorine in the feed water of SWRO with adequate mixing. Produced SWRO permeate was neutralized with $\mathrm{NaOH}$ before its discharge back to the 
129 Experiments were conducted at three conditions: (1) Baseline (BL); (2) After cleaning in place 130 (After CIP); and (3) Low coagulant dose (LD). The details of each experimental condition are 131 shown in Table 1. CIP was conducted by a series of caustic and acidic cleaning listed in Table 2.

132 During each experiment, the transmembrane pressure (TMP) of SWRO system was continuously 133 recorded under an initial permeate flux of $13 \mathrm{~L} / \mathrm{m}^{2} . h$. Samples were taken from the locations 134 presented in Figure 1 in the section 2.1 under each condition for quality analyses to investigate 135 the performance of each treatment step, especially the variation of TEP substances within the 136 treatment scheme.

137 In order to investigate the impact of chlorination on the TEP concentration in water, the 138 chlorination was disabled for 30 minutes during the "After CIP" condition and then samples 139 were taken to compare with those taken when chlorination was enabled.

Table 1: Experimental parameters applied in different conditions.

\begin{tabular}{lllllll}
\hline $\begin{array}{l}\text { Experimental } \\
\text { conditions }\end{array}$ & Membrane & Period & $\begin{array}{l}\text { Chlorine dose } \\
(\mathrm{mg} / \mathrm{L})\end{array}$ & $\begin{array}{l}\text { Chlorine } \\
\text { residuals } \\
(\mathrm{mg} / \mathrm{L})\end{array}$ & $\mathrm{pH}$ & $\begin{array}{l}\text { Coagulant dose } \\
(\mathrm{mg} / \mathrm{L})\end{array}$ \\
\hline BL & new & Dec 2014-Jan 2015 & 2.0 & 0.8 & 6.5 & 1.0 \\
After CIP & fouled & Jan-Feb 2015 & 2.0 & 0.8 & 6.5 & 1.0 \\
LD & new & Feb-Mar 2015 & 1.5 & 0.5 & 6.5 & 0.25 \\
\hline
\end{tabular}

142

144 Table 2: Cleanings conducted during CIP.

\begin{tabular}{lllllll}
\hline $\begin{array}{l}\text { Type of } \\
\text { cleaning }\end{array}$ & Chemical & $\begin{array}{l}\text { Concentration } \\
(\mathrm{wt} \%)\end{array}$ & $\mathrm{pH}$ & $\begin{array}{l}\text { Duration } \\
(\mathrm{min})\end{array}$ & $\begin{array}{l}\text { Flow } \\
\left(\mathrm{m}^{3} / \mathrm{hr}\right)\end{array}$ & $\begin{array}{l}\text { Pressure } \\
(\mathrm{bar})\end{array}$ \\
\hline Caustic & $\mathrm{NaOH}$ & 0.1 & 9 & 30 & 0.5 & 2.8 \\
Acidic & Citric acid & 2 & 4 & 30 & 0.5 & 2.8 \\
\hline
\end{tabular}

147 Water temperature, $\mathrm{pH}$, conductivity, turbidity and residual chlorine were measured twice daily.

148 Total iron was measured using an inductively coupled plasma optical emission spectrometry 149 (ICP-OES) (Varian 720ES ICP optical Emission Spectrometer). Total organic carbon (TOC) and 150 dissolved organic carbon (DOC) were measured using a TOC analyzer (Shimadzu TOC-VCPN). 151 DOC was determined by a pre-filtration with $0.45 \mu \mathrm{m}$ filters. In terms of the concentrations of 152 different fractions of DOC, they were analyzed by liquid chromatography-organic carbon 153 detection (LC-OCD), from DOC-LABOR Dr. Huber. The principle of the LC-OCD is size 
exclusion chromatography, and the definition of different organic fractions and their concentration calibration was based on the reported paper of Huber et al., [22]. The bacterial count was conducted by a flow cytometer (ACURRI C6 from BD Company) using SYBR Green dyes for live cells.

Particulate TEP (P-TEP, $>0.4 \mu \mathrm{m})$ and colloidal TEP precursors (C-TEP, 0.1-0.4 $\mu \mathrm{m}$ ) were measured with a dye binding spectrophotometric assay developed by Passow and Alldredge [5]. This method was developed for the P-TEP quantification, but the authors extend this method to C-TEP by filtering the $0.4 \mu \mathrm{m}$ permeate of samples on $0.1 \mu \mathrm{m}$ membrane of the same material (polycarbonate). After filtration, the binding process, color elusion with sulfuric acid, and detection with UV spectrometer were identical as the described method for P-TEP.

Regarding TEP measurements, two calibration curves using xanthan gum as equivalent compound were developed for P-TEP and C-TEP, respectively. Xanthan Gum stock solution was prepared by dissolving xanthan gum in milli-Q water and filtering it through $1.2 \mu \mathrm{m}$ filters, and TOC concentration of prepared stock solution was analyzed as well. A series of known volume of gum stock solutions were firstly filtered through $0.4 \mu \mathrm{m}$ polycarbonate filters (for P-TEP) and then $0.1 \mu \mathrm{m}$ filter (for C-TEP), and the TOC of 0.1 and $0.4 \mu \mathrm{m}$ permeate were detected to calculate the amount of xanthan gum on 0.1 and $0.4 \mu \mathrm{m}$ polycarbonate membranes. The membranes with rejected TEP were stained with $0.06 \%(\mathrm{~m} / \mathrm{v})$ alcian blue dye, and then flushed with milli-Q water to flush away the excess dye which was not bond to TEP. These membranes were submerged in $6 \mathrm{ml}$ of $80 \%$ sulfuric acid for 3-4 hours with gentle shaking to elucidate the bond dye on TEP, and consequently the sulfuric acid with elucidated color was detected for UVVisible absorption at $789 \mathrm{~nm}$ (Shimadzu-UV 2250). The more TEP on membranes, the higher the UV absorption is.

\section{Results and discussion}

3.1 Performance of the pilot plant

The incoming seawater quality into the pilot facility is shown in Table 3. Most of the water quality parameters of the Red Sea water were consistent during this study, except for the turbidity. Although the turbidity of feed seawater significantly fluctuated over time, it was significantly reduced down to lower than 1 NTU after the DMF for all the three phases of experiments. Because of the acidification of seawater for coagulation, the $\mathrm{pH}$ of seawater after 
chemical addition was reduced from 8 down to around 6.5, and was constant along with the whole pretreatment. The temperature and conductivity were also consistent during pretreatments.

Table 3: Water quality of feed seawater.

\begin{tabular}{ll}
\hline & Feed seawater \\
\hline Temperature $\left({ }^{\circ} \mathrm{C}\right)$ & $25 \pm 1$ \\
pH & $8 \pm 0.1$ \\
Turbidity $(\mathrm{NTU})$ & $2-50$ \\
Conductivity $(\mathrm{mS} / \mathrm{cm})$ & $59 \pm 1$ \\
TOC $(\mathrm{mg} / \mathrm{L})$ & $1.15 \pm 0.06$ \\
$\mathrm{P}-\mathrm{TEP}(\mu \mathrm{g}$ xanthan gum eq./L) & $190 \pm 15$ \\
$\mathrm{C}-\mathrm{TEP}(\mu \mathrm{g}$ xanthan gum eq./L) & $150 \pm 10$ \\
\hline
\end{tabular}

Regarding the performance of the SWRO unit, Figure 2 shows the salt rejection (conductivity) and system recovery for the spiral wound SWRO membranes for all the three conditions of experiments. The system was operated at an average recovery rate of $38 \%$, which is consistent with the set value mentioned in section 2.1. Salt rejection was stable at around $98 \%$ in all experiments. Therefore, the performance of RO membranes on salt removal was satisfying.

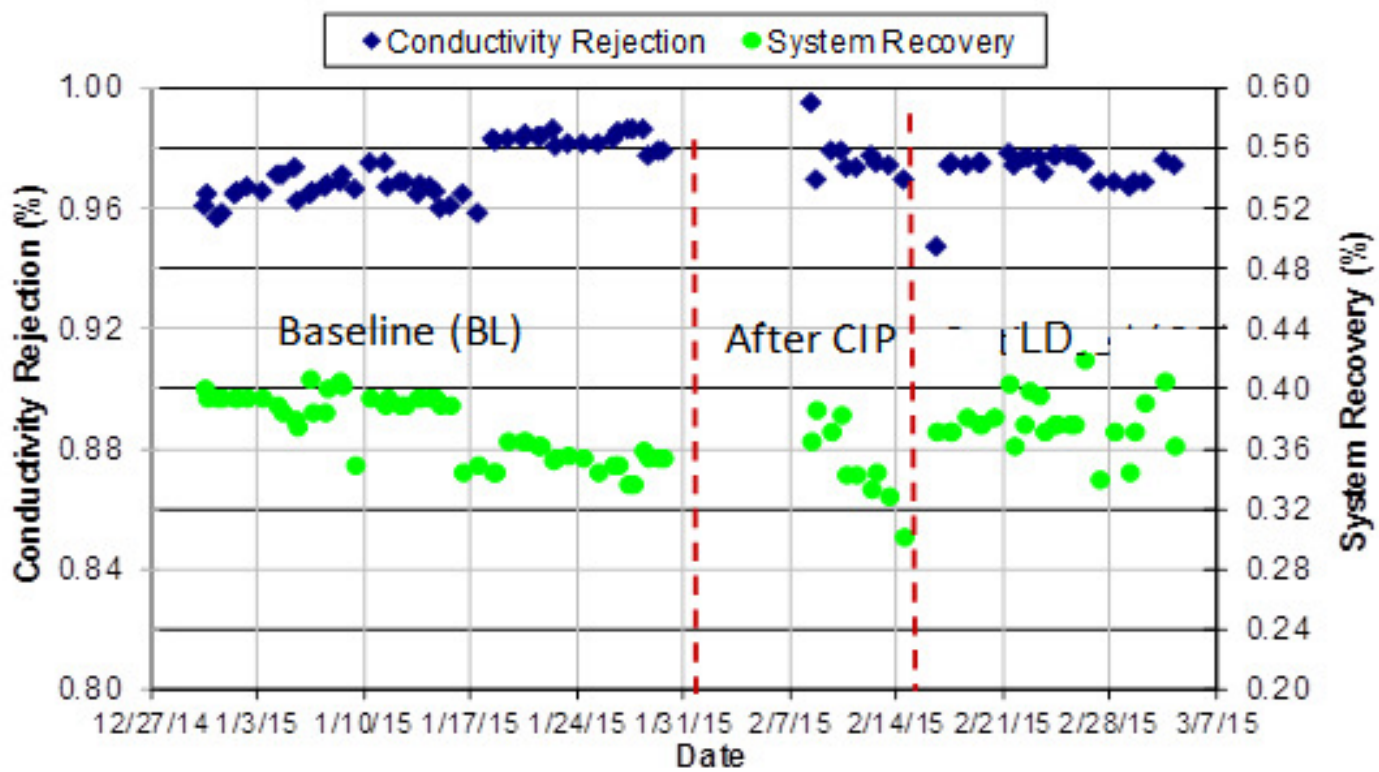

196

197 Figure 2: Salt rejection (conductivity) and system recovery for RO membranes. 
Within the $1.15 \mathrm{mg} / \mathrm{L}$ TOC of the feed seawater, particulate organic carbon was only a small fraction. Figure 3(a) shows the DOC of feed seawater for all conditions, which were about 1.0, 1.1 and $1.12 \mathrm{mg} / \mathrm{L}$ for BL, After CIP and LD conditions, respectively. As shown in Figure 3(a), after chemical addition (i.e., coagulation and acid addition) and DMF, part of the DOC was removed. However, the amounts of DOC removed by the BL and After CIP periods were much higher (24-31\%) compared to the LD condition (8\%). This was consistent with the jar-test results for Red Sea water reported elsewhere [23]. The higher DOC removal for BL and After CIP period is probably due to the higher amount of the coagulant dose $\left(1.0 \mathrm{mg} / \mathrm{L}\right.$ as $\left.\mathrm{Fe}^{+3}\right)$ than the LD period $\left(0.25 \mathrm{mg} / \mathrm{L}\right.$ as $\left.\mathrm{Fe}^{+3}\right)$. Dissolved organics in seawater, especially TEPs, were negatively charged acidic polysaccharides and proteins; the presence of cationic coagulant substantially reduced the electrical double layer on the negatively charged TEPs, and thus lowered the repulsion force between them. Consequently, they formed larger particles during ferric coagulation. Because the high dosage of coagulant in BL and After CIP conditions, a stronger charge screening effect of dissolved organics could be established, leading to more formations of particulate organics. The formed particulate organics could be better removed by DMF, so that the reduction of DOC in BL and After CIP conditions was higher than the LD condition. Compared to the LD condition, more biopolymers and humics were removed during the BL condition, which was consistent with the variation of DOC detected by the TOC analyzer. Similar with the conductivity (salt) rejection, SWRO membranes were effective in removing most of DOC (97-98\%).

Table 4 shows different constituents of the dissolved organic matter measured by LC-OCD for the BL and LD conditions. Both constituents were reduced during pre-treatment with a similar percentage, but a larger portion of humics were removed due to their higher initial concentrations. The reduction of biopolymers and humics was because of the aggregation of humics and the consequent removal of formed particles by pretreatment.

Table 4: Sub fractions of DOC at different locations of the treatment scheme for BL and LD conditions measured by the LC-OCD.

\begin{tabular}{lcccc}
\hline & \multicolumn{2}{c}{ Biopolymer $(p p b)$} & \multicolumn{2}{c}{ Humics $(p p b)$} \\
\hline & BL & LD & BL & LD \\
\hline Seawater & 151 & 137 & 1003 & 770 \\
After chem & 74 & 94 & 596 & 550 \\
After DMF & 72 & 104 & 600 & 538
\end{tabular}


\begin{tabular}{lllll} 
RO feed & 102 & 163 & 692 & 805 \\
\hline
\end{tabular}

$\begin{array}{lllll}\text { RO concentrate } & 145 & 252 & 1059 & 1389\end{array}$

228 Figure 3(b) shows the bacteria number during various phases of the piloting and from various

229 locations. Seawater contains a large amount of microbial populations, which ranges to about $2307,000-11,000$ cells/ $\mu \mathrm{L}$. Most of the microbial population was eliminated by chlorination. After 231 DMF, the bacterial count is found to be negligible. The bacteria number in SWRO permeate was 232 kept nil for the whole experiment, indicating the rejection of bacteria of SWRO membranes also 233 met the requirements of seawater desalination for portable use. 

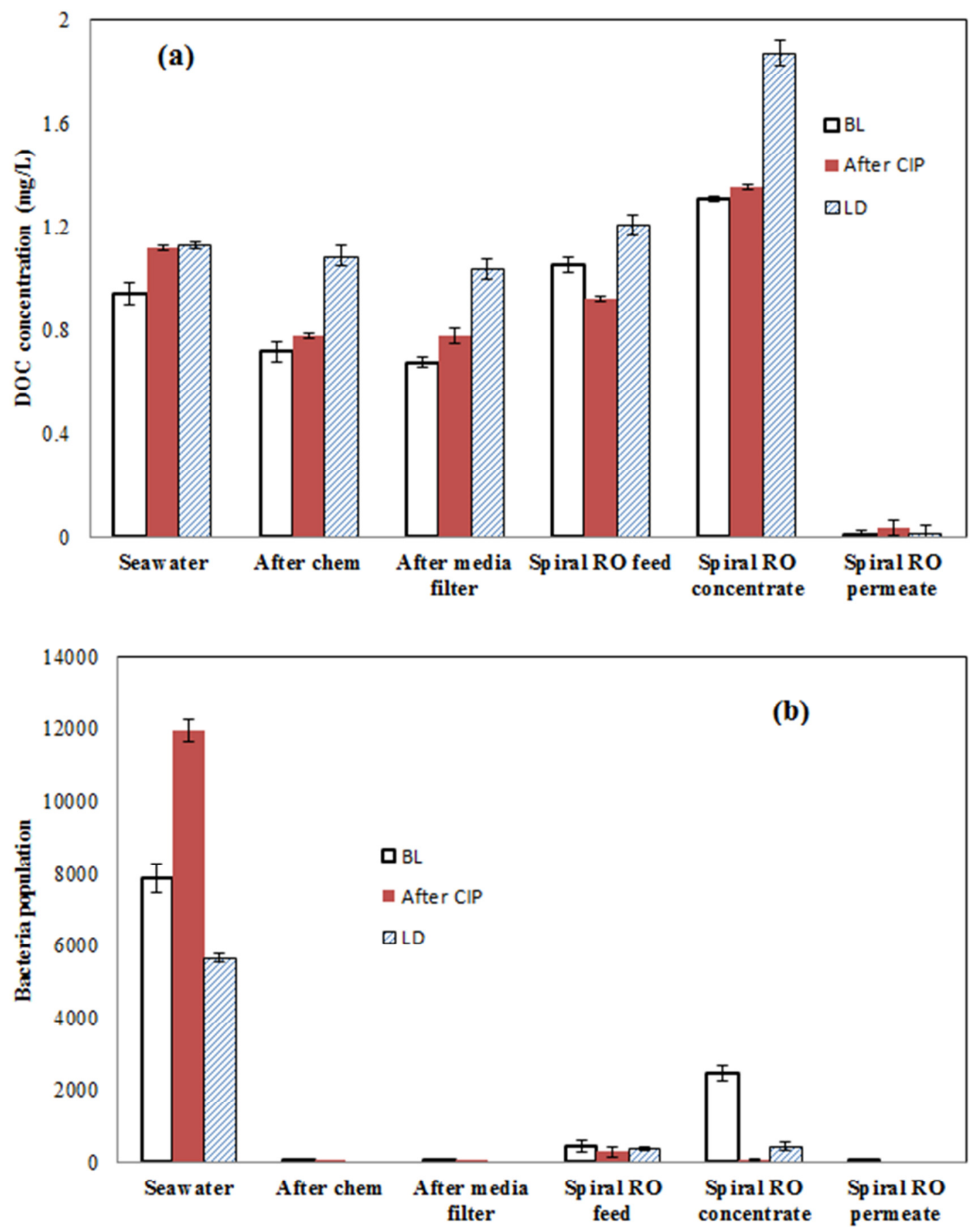

236 Figure 3: Variation along the treatment scheme for (a) DOC concentration; and (b) bacteria cell 237 count. 
239 Although SWRO membrane filtration could produce high quality permeate with low salinity 240 [24], and no DOC and bacteria, RO membranes fouling was a significant issue in operating the 241 pilot plant. Figure 4 shows the TMP and flux over time for BL after CIP and LD experimental 242 conditions. This Figure shows the increase of TMP with time during operation, while the flux 243 decreases due to fouling (or scaling). A rise in TMP and decrease in flux are shown to be more 244 for the BL condition than that of the LD condition, as shown in Figure 4. Similar trends for the 245 period after CIP was observed, indicating the CIP cleaning was not able to restore the flux or 246 lowering the TMP. The TMP remains high for both BL and after CIP, whereas the LD condition 247 was found to provide better performance with stable TMP and flux. That was probably related to 248 the amount of TEP/TEP precursors in RO feed water, which was influenced by the residual free 249 iron under different experimental conditions.

250 Some of the strategies were adapted in practice to control the SWRO membrane fouling, such as 251 chlorination and cartridge filtration before RO (used as a final check in order to protect the RO 252 membranes). Chlorination was applied in this study to reduce the bioactivity in the seawater, so 253 that the biofouling in RO membranes could be eliminated or reduced. It is also a common 254 practice in the desalination plants installed along the Red Sea coast. Cartridge filters are 255 normally used as a final barrier to guarantee the RO feed is particle free and protect RO 256 membranes from fouling. However, their functions in reality may not be as what people 257 expected. The monitored particulate and colloidal TEP concentrations along the treatment 258 scheme unfolded the other sides of these fouling control strategies (see next sections). 


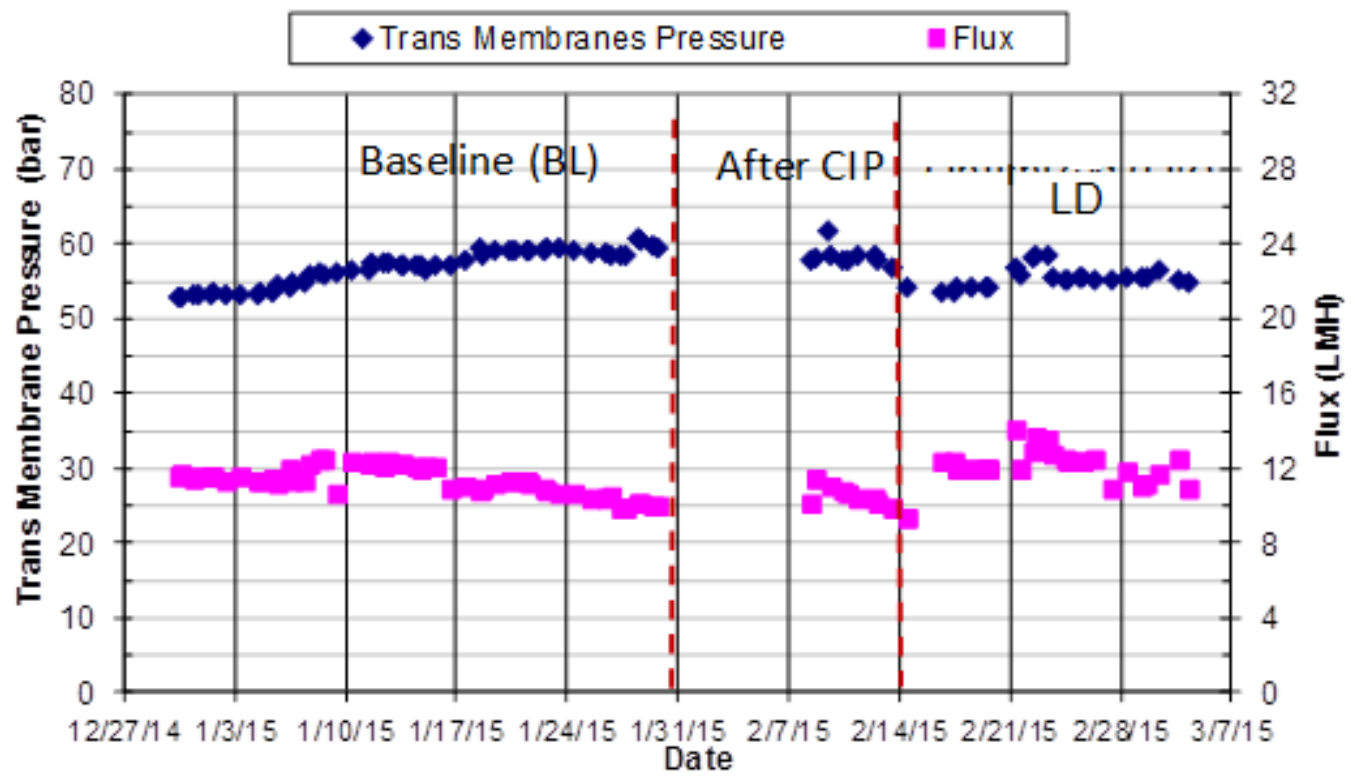

259

260 Figure 4: Trans-membrane pressure and flux as a function of time for the three phases.

261

262

263

3.2 Impact of chlorination on the concentration variation of TEP/TEP precursors in treatment scheme.

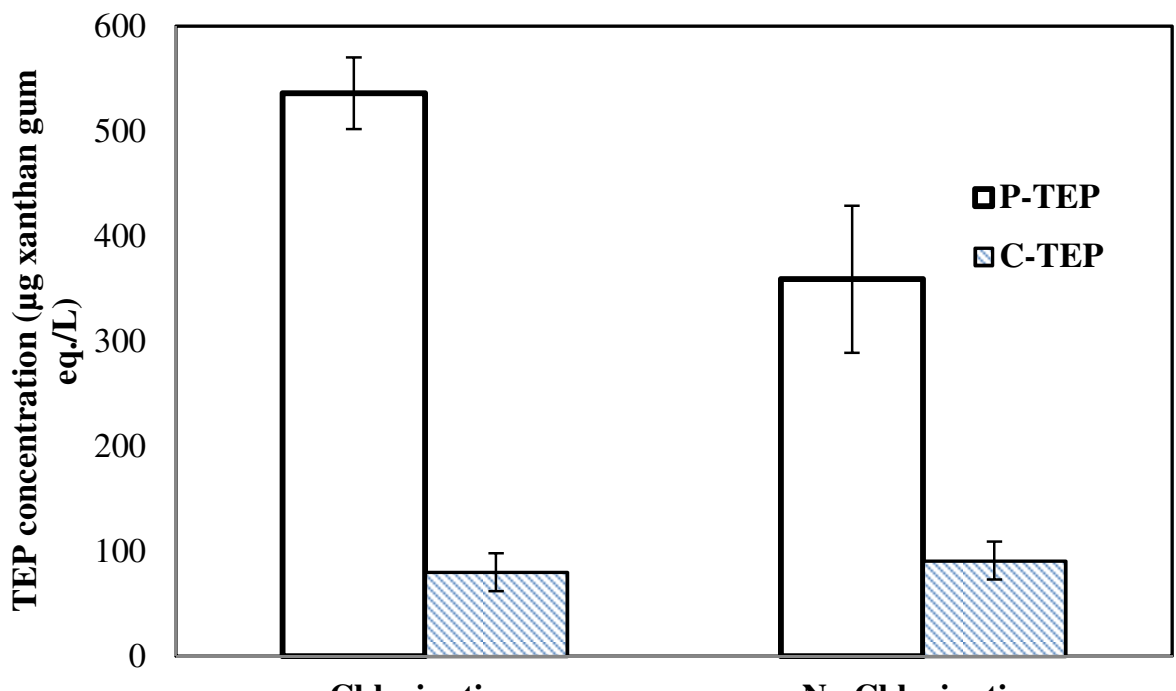

Chlorination

No Chlorination

265 Figure 5: Particulate and colloidal TEP concentrations with chlorination and without

266 chlorination, during "After CIP" experimental condition with $2.0 \mathrm{mg} / \mathrm{L}$ chlorine and $1.0 \mathrm{mg} / \mathrm{L}$

$267 \mathrm{Fe}^{3+}$ coagulant doses. 
Figure 5 shows the P-TEP and C-TEP concentrations under the circumstances with and without chlorination. The P-TEP concentration after chlorination $(536 \mu \mathrm{g}$ xanthan gum eq./L) is about $30 \%$ more than the one without chlorination (359 $\mu \mathrm{g}$ xanthan gum eq./L), while the C-TEP concentrations were on the same level for both cases. This phenomenon indicated that the chlorine resulted in more TEP release into the seawater. That was probably because the cells of bacteria in seawater were broken down by the chlorine and some polymeric substances inside of the cells were released, and contributed to the pool of P-TEP in seawater. It was also possible that C-TEP was released from the damaged bacterial cells, and then because of the coagulation, C-TEP aggregated and formed P-TEP, the difference between with and without chlorination on TEP concentration may mainly be reflected as P-TEP.

TEP has been reported as a main fouling factor for SWRO membrane filtration. Although the amount of bacteria was reduced down to zero after chlorine injection, more potential foulants were produced at the same time. On one hand, more TEP production might cause the clogging of the pretreatment systems, such as DMF and/or UF. On the other hand, TEP substances can be utilized by bacteria as nutrient (both $\mathrm{C}$ and $\mathrm{N}$ sources) for their growth, promoting a biofilm formation. If there is no bacteria present in the downstream SWRO after chlorination, the more produced TEP might not be an issue for SWRO biofouling, because the biofilm formation requires the presence of bacteria. However, some of the bacteria can adapt/resist to chlorine, and become inactive instead of real dying after the chlorine dosage [21]. These bacteria may accumulate in the following cartridge filters and/or RO membranes. When the residual chlorine is quenched by the SBS, these accumulated bacteria may become active again. In that case, they can have more TEP substances to utilize for their growth and enhance the biofouling of RO membranes.

The regrowth of bacteria after quenching residual chlorine has been detected in this study. As shown in Figure 3(b), the detected bacteria number increased again from about zero in the DMF permeate up to 500 cells $/ \mu \mathrm{L}$ in the SWRO feed. In this pilot, the residual chlorine was quenched by SBS before the cartridge filters. The increased bacteria population indicated the bacteria regrowth in the system after quenching the residual chlorine. According to this study, the TEP/TEP precursors concentrations were increased by the chlorination due to the release of polymeric organics from the damaged cells of bacteria. The increases in TEP/TEP precursors after chlorination could cause a more sever organic fouling on the downstream filtration, using 
either conventional DMF or MF/UF pretreatments. The cartridge filter might be clogged due to the increased organics loading, leading to a more frequent replacement. If some of the TEP/TEP precursors pass through all pretreatment steps, it might cause organic fouling on SWRO membranes as well. Regarding the RO membrane biofouling, the increase of TEP/TEP precursors after chlorination does not definitely enhance the biofilm formation, since it also depends on the chlorine adaptability of bacteria and the location where SBS is injected for quenching the residual chlorine.

However, in this study, due to the clear regrowth of bacteria after cartridge filters, the high flux decline during the "After CIP" condition was probably caused by both the organic fouling of TEP/TEP precursors and the consequently enhanced biofilm formation on RO membranes.

\subsection{Fouling deterioration from cartridge filters}

Figure 6 shows the P-TEP and C-TEP concentrations before and after cartridge filtration. Before the cartridge filtration, around $300 \mu \mathrm{g}$ xanthan gum eq./L P-TEP and C-TEP were present in the DMF permeate, indicating the insufficient removal of TEP substances by DMF. A lower or at least equal TEP concentration should be expected for the water after cartridge filtration, but about $700 \mu \mathrm{g}$ xanthan gum eq./L TEP was detected in the water after cartridge filter (SWRO feed). Normally, the function of cartridge filtration is to make sure that the required RO feed water quality is met by preventing any remaining big particles or suspended solids which were not removed in pretreatment entering into $\mathrm{RO}$ membranes and consequently prevent severe membrane fouling. However, we observed that more TEP substances were produced within the cartridge filter, which degraded the upstream pretreatment.

It is interesting to observe that the DOC concentration and bacteria number in RO feed water was also higher than that of the DMF effluent, indicating some bioactivities within the cartridge filter between DMF and SWRO feed. TEP substances are also organic carbon, and the increase of TEP concentration was consistent with the increase of DOC after cartridge filter, as shown in Figure 3(a). The increase of bioactivities and thus more TEP production within the cartridge filters was probably because of two reasons: i) the quenching of residual chlorine by SBS dosage and ii) dosage of phosphate based antiscalant. It has been reported that the dosing of phosphate based antiscalant can cause biofouling of RO membranes [25]. 

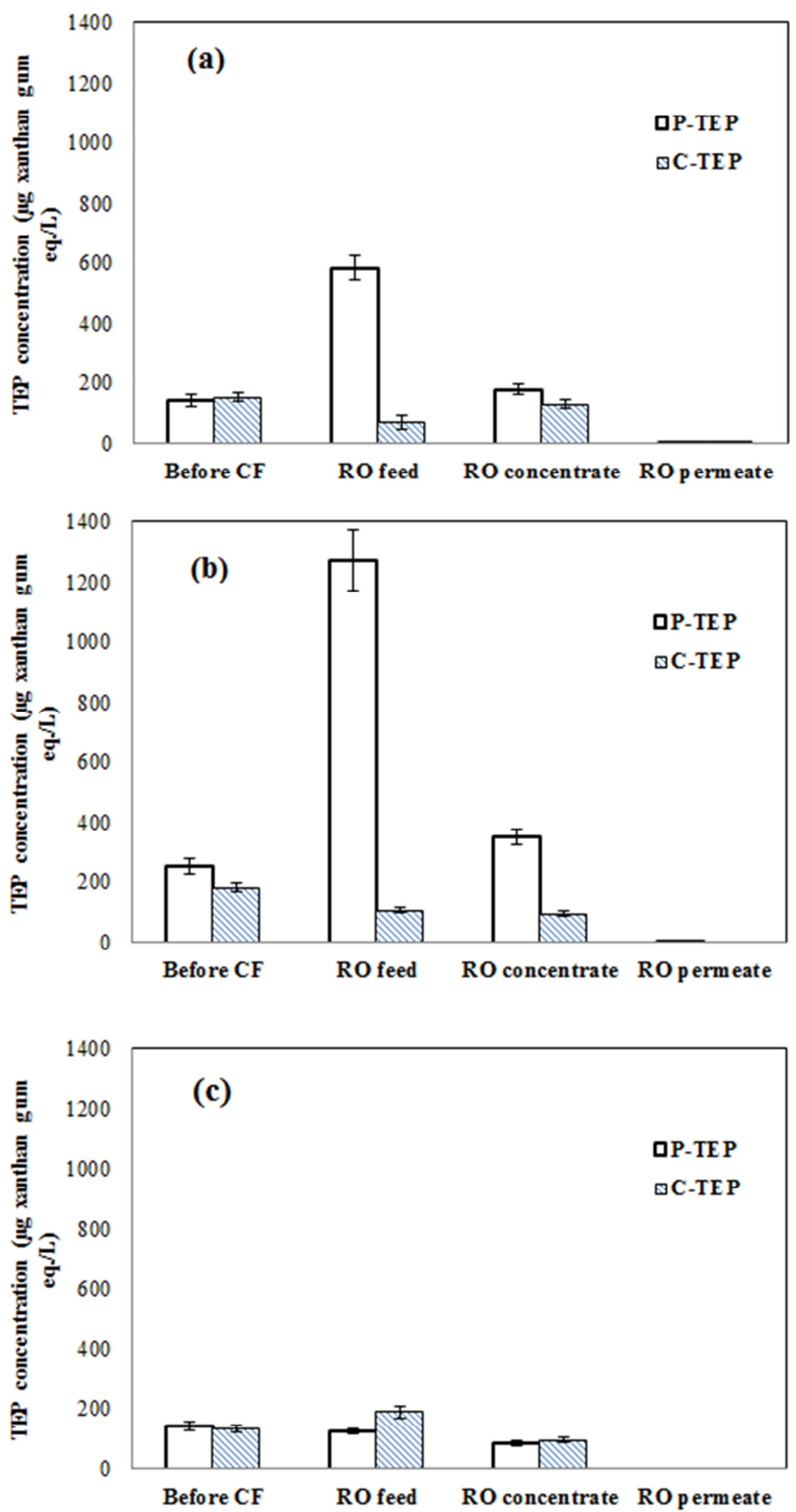

332 Figure 6: Particulate and colloidal TEP concentrations at different locations (Before CF, RO 333 feed, RO concentrate and RO permeate) for (a) BL, (b) After CIP, and (c) LD condition. 
In regular $\mathrm{RO}$ membrane desalination plants, in order to protect the $\mathrm{RO}$ membranes from damage via oxidation by chlorine, SBS is dosed before the cartridge filter to quench the residual chlorine. However, some of the bacteria adapts to the dosage of chlorine. These bacteria are just deactivated under chlorination [21]. When the residual chlorine is quenched by SBS, they might recover their activity. Because most of the material of cartridge filters is cellulose acetate, which can provide a large space for bacteria adsorption, it is very likely that these reactivated bacteria nested and grown within the filters. During the growth of bacteria, TEP substances and some other organic compounds could be released. As a consequence, a higher TEP and DOC concentrations were detected in the RO feed water. Since the cartridge filter seems to serve as a hub for bacteria growth, it might be better to spike the SBS after, instead of before, the cartridge filters.

Regarding the dosage of antiscalant, it might not be the direct reason of bacteria growth within the cartridge filter. An antiscalant is normally added in seawater to prevent the saturation of multivalent cations (precipitation of salts) on the surface of spiral-wound RO membranes. The antiscalant added was phosphate based, while phosphate is essential for the bacteria growth [25]. The addition of phosphate might provide the necessary component for reactivated bacteria adsorbed on the cartridge filters.

\subsection{Impact of free iron residual on the TEP}

Although the problem of cartridge filters applied to all the three experimental conditions, the increase of P-TEP and C-TEP was not the same. As shown in Figure 6, during the BL and After CIP conditions, more P-TEP were formed after the cartridge filters. On the other hand, there was more C-TEP than P-TEP during the LD condition. This difference was probably caused by the different residual free iron in the $\mathrm{RO}$ feed water.

The total dissolved residual iron profiles for the BL, After CIP and LD conditions of various samples collected from various locations within the pilot-plant, as presented in Table 5. This table shows that the residual iron during the BL and After CIP were higher than the LD condition. The free iron content in SWRO feed for the BL and After CIP conditions far exceed the one for LD condition. Therefore, during these two conditions, there was more free iron to interact with the C-TEP. The higher increase in P-TEP due to aggregation would probably led to the higher deposition of TEP on the RO membranes, and thus a more severe membrane fouling. 
367 Table 5: Dissolved residual iron $\left(\mathrm{Fe}^{+3}\right.$ in $\left.\mathrm{mg} / \mathrm{L}\right)$ at various locations of the pilot plant during the 368 three experimental periods.

369

\begin{tabular}{llll}
\hline & RO feed & RO concentrate & RO permeate \\
\hline BL & 0.05 & 0.058 & $<0.001$ \\
After CIP & 0.13 & 0.059 & $<0.001$ \\
LD & $<0.001$ & 0.015 & $<0.001$ \\
\hline
\end{tabular}

\subsection{Deposition of TEP/TEP precursors on SWRO membranes}

Figure 6 shows the variation of TEP concentration within the SWRO unit. It is clear that all the TEP substances were rejected by the RO membranes, so both P-TEP and C-TEP concentrations in the RO permeate were almost nil. Because of the $38 \%$ recovery, the concentration of rejected organic substances in RO concentrate should be higher than that in RO feed. Theoretically, if there is no deposition on the membrane surface, the organics concentration would be 1.61 times higher than the feed. It has been shown by the DOC measurements that organics' concentration of RO concentrate increased for all the three phases of experiments (see Figure 3). However, the increases were not as high as the theoretical calculation. The DOC increases in RO concentrate for all the three phases (BL, After CIP and LD) were 1.25, 1.47, and 1.55 times higher than the corresponding RO feed, respectively. The measured DOC increases in RO concentrate were smaller than the theoretical value, indicating the deposition of organics on the membrane surface. On the other hand, the TEP concentration in RO concentrate was much lower than the one of RO feed. Since no TEP substances passed through the RO membranes, it indicates that the TEP substances were deposited on the RO membranes.

The flux decline for the BL and After CIP conditions was more severe than of that observed for the LD condition (see Figure 4). The higher flux decline for BL and After CIP conditions was associated with more TEP in the RO feed water (Figure 6), and more TEP deposition on the RO membranes. This indicates that there is a proportional relationship between TEP substances in RO feed and RO membrane fouling. This confirms the hypothesis about the high fouling potential of TEP substances on membranes, and consistent with the results reported by other researchers $[14,26]$.

RO membrane fouling is a complicated issue, and it could be the result of several impacts. Based on the results in this study, TEP is a critical contributor to the RO membrane fouling. However, this TEP fouling could also be influenced by the residual iron in water. The difference between 
$\mathrm{BL}$ and $\mathrm{LD}$ condition was the amount of iron based on coagulant dosage. Because there was some residual free iron in the pretreated water after coagulation, this residual irons might react with the low molecular weight organics and form some bigger particles (such as P-TEP) to foul the RO membranes. The variation of iron residual in pretreated water among different experimental conditions is proportionally related to the corresponding normalized flux decline.

\section{Conclusions}

The variation of TEP/TEP precursors concentration along a conventional SWRO treatment scheme was evaluated in this study. It has been found that the RO membrane fouling increased with the increment of TEP/TEP precursors' concentration in RO feed water.

Chlorination was effective in reducing bacterial populations till before the cartridge filters for all the three scenarios (BL, after CIP and LD period), but chlorination has also caused a higher TEP release into the RO feed seawater by destroying the cells of bacteria.

Moreover, TEP/TEP precursors concentration was increased after cartridge filters. That was probably because SBS was dosed to quench the residual chlorine before the cartridge filter, and thus deactivated bacteria by chlorination recovered their activity. Consequently, the recovered bacteria might utilize the cartridge filter as an incubator for its growth and release TEP/TEP precursors. Since phosphate is an essential element for bacteria growth, addition of phosphate based antiscalant before the cartridge filter may also have enhanced the bioactivity and TEP production within the cartridge filters, leading more fouling on the SWRO membranes.

A higher coagulant dosage $\left(1.0 \mathrm{mg} / \mathrm{L}\right.$ as $\left.\mathrm{Fe}^{+3}\right)$ reduced more dissolved organic carbon than the low dosage $\left(0.25 \mathrm{mg} / \mathrm{L}\right.$ as $\left.\mathrm{Fe}^{+3}\right)$. However, the more residual iron at the high dosage (if not controllable, passing through DMF) might interact with the dissolved TEP precursors present in RO feed, which led to a more severe RO membrane fouling.

\section{Acknowledgement}

Center Industry Affiliates Program (CIAP) of the Water Desalination and Reuse Center (WDRC) at King Abdullah University of Science and Technology (KAUST) is acknowledged for the financial support of this project.

\section{References}


426 [1] N. Ghaffour, T.M. Missimer, G.L. Amy, Technical review and evaluation of the economics of water

427 desalination: Current and future challenges for better water supply sustainability, Desalination, 309

428 (2013) 197-207.

429 [2] T. Berman, Biofouling: TEP - a major challenge for water filtration, Filtration and Separation, 47

430 (2010) 20-22.

431 [3] T. Berman, M. Holenberg, Don't fall foul of biofilm through high TEP levels, Filtration and 432 Separation, 42 (2005) 30-32.

433 [4] T. Berman, R. Mizrahi, C.G. Dosoretz, Transparent exopolymer particles (TEP): A critical factor in 434 aquatic biofilm initiation and fouling on filtration membranes, Desalination, 276 (2011) 184-190.

435 [5] U. Passow, A.L. Alldredge, A dye-binding assay for the spectrophotometric measurement of 436 transparent exopolymer particles (TEP), Limnology and Oceanography, 40 (1995) 1326-1335.

437 [6] U. Passow, Formation of transparent exopolymer particles, TEP, from dissolved precursor material, 438 Marine Ecology Progress Series, 192 (2000) 1-11.

439 [7] W.C. Chin, M.V. Orellana, P. Verdugo, Spontaneous assembly of marine dissolved organic matter into polymer gels, Nature, 391 (1998) 568-572.

441 [8] M.S. Wetz, P.A. Wheeler, Release of dissolved organic matter by coastal diatoms, Limnology and 442 Oceanography, 52 (2007) 798-807.

443 [9] U. Passow, Production of transparent exopolymer particles (TEP) by phyto- and bacterioplankton, 444 Marine Ecology Progress Series, 236 (2002) 1-12.

445 [10] A.L. Alldredge, U. Passow, B.E. Logan, The abundance and significance of a class of large, 446 transparent organic particles in the ocean, Deep-Sea Research Part I, 40 (1993) 1131-1140.

447 [11] S. Beauvais, M.L. Pedrotti, E. Villa, R. Lemée, Transparent exopolymer particle (TEP) dynamics in relation to trophic and hydrological conditions in the NW Mediterranean Sea, Marine Ecology Progress 449 Series, 262 (2003) 97-109.

450 [12] S. Li, H. Winters, L.O. Villacorte, Y. Ekowati, A.H. Emwas, M.D. Kennedy, G.L. Amy, 451 Compositional similarities and differences between transparent exopolymer particles (TEPs) from two 452 marine bacteria and two marine algae: Significance to surface biofouling, Mar. Chem., 174 (2015) 131453140.

454 [13] S. Li, H. Winters, S. Jeong, A.H. Emwas, S. Vigneswaran, G.L. Amy, Marine bacterial transparent 455 exopolymer particles (TEP) and TEP precursors: Characterization and RO fouling potential, Desalination, $456379(2016) 68-74$.

457 [14] L.O. Villacorte, M.D. Kennedy, G.L. Amy, J.C. Schippers, The fate of Transparent Exopolymer 458 Particles (TEP) in integrated membrane systems: Removal through pre-treatment processes and 459 deposition on reverse osmosis membranes, Water Research, 43 (2009) 5039-5052. 
[15] A. Alhadidi, A.J.B. Kemperman, R. Schurer, J.C. Schippers, M. Wessling, W.G.J. Van der Meer, Using SDI, SDI+ and MFI to evaluate fouling in a UF/RO desalination pilot plant, Desalination, 285 (2012) 153-162.

[16] A. Alhadidi, B. Blankert, A.J.B. Kemperman, R. Schurer, J.C. Schippers, M. Wessling, W.G.J. van der Meer, Limitations, improvements and alternatives of the silt density index, Desalination and Water Treatment, 51 (2013) 1104-1113.

[17] C.H. Wei, S. Laborie, R. Ben Aim, G. Amy, Full utilization of silt density index (SDI) measurements for seawater pre-treatment, Journal of Membrane Science, 405-406 (2012) 212-218.

[18] M.L. Richlen, S.L. Morton, E.A. Jamali, A. Rajan, D.M. Anderson, The catastrophic 2008-2009 red tide in the Arabian gulf region, with observations on the identification and phylogeny of the fish-killing dinoflagellate Cochlodinium polykrikoides, Harmful Algae, 9 (2010) 163-172.

[19] B. Karnaugh, J. Jaminet, B. Shelton, Membranes: TIME dI water reverse osmosis plant periodic direct chlorination- epilog, Ultrapure Water, 17 (2000) 39-44.

[20] E. Friedler, I. Katz, C.G. Dosoretz, Chlorination and coagulation as pretreatments for greywater desalination, Desalination, 222 (2008) 38-49.

[21] M.T. Khan, P.Y. Hong, N. Nada, J.P. Croue, Does chlorination of seawater reverse osmosis membranes control biofouling?, Water Research, 78 (2015) 84-97.

[22] S.A. Huber, A. Balz, M. Abert, W. Pronk, Characterisation of aquatic humic and non-humic matter with size-exclusion chromatography - organic carbon detection - organic nitrogen detection (LC-OCDOND), Water Research, 45 (2011) 879-885.

[23] S. Li, S.-T. Lee, S. Sinha, N. Ghaffour, Effect of coagulation on aggregating colloidal transparent exopolymer particles (TEP) released from marine bacteria, in: EuroMed 2015 Desalination for Clean Water and Energy, Palermo, Italy, 2015.

[24] Y. Gacem, S. Taleb, A. Ramdani, S. Senadjki, N. Ghaffour, Physical and chemical assessment of MSF distillate and SWRO product for drinking purpose, Desalination, 290 (2012) 107-114. [25] J.S. Vrouwenvelder, F. Beyer, K. Dahmani, N. Hasan, G. Galjaard, J.C. Kruithof, M.C.M. Van Loosdrecht, Phosphate limitation to control biofouling, Water Research, 44 (2010) 3454-3466. [26] M.D. Kennedy, F.P. Muñoz Tobar, G. Amy, J.C. Schippers, Transparent exopolymer particle (TEP) fouling of ultrafiltration membrane systems, Desalination and Water Treatment, 6 (2009) 169-176. 